\title{
Yanick Lahens, Bain de lune
}

\section{Carminella Biondi}

\section{(2) OpenEdition \\ 1 Journals}

\section{Edizione digitale}

URL: http://journals.openedition.org/studifrancesi/987

DOI: 10.4000/studifrancesi.987

ISSN: 2421-5856

\section{Editore}

Rosenberg \& Sellier

\section{Edizione cartacea}

Data di pubblicazione: 1 agosto 2015

Paginazione: 423-424

ISSN: 0039-2944

\section{Notizia bibliografica digitale}

Carminella Biondi, « Yanick Lahens, Bain de lune », Studi Francesi [Online], 176 (LIX | II) | 2015, online dal 01 août 2015, consultato il 18 septembre 2020. URL : http://journals.openedition.org/studifrancesi/ 987 ; DOI : https://doi.org/10.4000/studifrancesi.987

Questo documento è stato generato automaticamente il 18 settembre 2020.

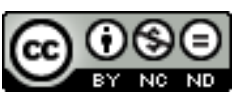

Studi Francesi è distribuita con Licenza Creative Commons Attribuzione - Non commerciale - Non opere derivate 4.0 Internazionale. 


\title{
Yanick Lahens, Bain de lune
}

\author{
Carminella Biondi
}

\section{NOTIZIA}

YANICK LAHENS, Bain de lune, Paris, Sabine Wespieser éditeur, 2014, pp. 271.

1 Il romanzo della scrittrice haitiana ha meritatamente ottenuto il «Prix Femina» 2014. Racconta una lunga storia che oscilla fra realtà e mistero, come tutte le storie che fioriscono in terra haitiana dove i confini fra i due mondi sono molto labili e gli sconfinamenti fanno parte del vissuto quotidiano. Già le prime pagine fotografano questa compresenza: il romanzo apre infatti - con una frase misteriosa: «Après une folle équipée de trois jours, me voilà étendue là, aux pieds d'un homme que je ne connais pas» (p.7) - su una scena che intuiamo essere drammaticamente reale, ma che resta tuttavia avvolta nel mistero, perché non è chiara la condizione della donna che si esprime in prima persona, dal momento che non è in grado né di parlare né di muoversi nella realtà, e neppure è chiaro il suo rapporto con l'uomo sconvolto, in piedi davanti a lei. Il senso della scena si preciserà a poco a poco nel corso del racconto. La donna immobile sulla spiaggia, presumibilmente morta, può però ricordare e vuole farlo, per rimettere «au monde un à un [ses] aïeuls et aïeules» (p. 9). In questa operazione di lento recupero del passato, la narratrice sa che deve tenere conto anche degli elementi naturali, perché condizionano in maniera feroce la vita degli abitanti dell'isola in cui è ambientata la storia, un'isola ormai desertificata: «Quel ouragan! Quel tumulte! Dans toute cette histoire il faudra tenir compte du vent, du sel, de l'eau, et pas seulement des hommes et des femmes» (p. 9).

2 Scopriremo soltanto al trentunesimo capitolo (sono in tutto 43) l'identità e la condizione della donna che parla: si tratta di Cétoute Olmène Thérèse, una delle ultime discendenti della famiglia Lafleur, la cui storia si intreccia, nel bene e nel male (più nel male che nel bene) con quella dei Mésidor, il cui ultimo rampollo, Jimmy, seduce e uccide Cétoute, come il nonno aveva sedotto, in anni lontani, Olmène, nonna di Cétoute, fuggita da Haiti per sottrarsi alla prepotenza del despota Mésidor, la cui assenza aleggia 
come un fantasma nei ricordi dei Lafleur. Alla fine del romanzo c'è un albero genealogico delle due famiglie, che aiuta il lettore a non perdersi all'interno delle varie storie e delle varie epoche che si intersecano e si susseguono. C'è anche un glossaire che ci permette di capire il significato di alcune parole intraducibili.

3 Colei che racconta è dunque una giovane morta che, non essendo ancora stata sottoposta al rito di addio da parte della sua famiglia, non può varcare il confine che le permetterà di entrare definitivamente nel mondo degli Invisibili. Attraverso l'alternanza di presente e passato, indicata anche visivamente nell'alternanza di caratteri (il presente è narrato in corsivo), si ricostruisce, grazie al ricordo e alle visioni di un'adolescente rimasta a metà del guado fra la vita e la morte, la storia lunga quasi un secolo (dalla prima occupazione americana ad Aristide) di due famiglie: quella degli oppressi Lafleur e quella degli oppressori Mésidor, nelle quali si riassume la storia corale del popolo haitiano, un popolo sfiduciato e tuttavia sempre pronto a lasciarsi affascinare dai falsi profeti: prima Duvalier ("l'homme à chapeau et lunettes noires"), poi Aristide ("le prophète des Démunis") che promettono miracoli e trascinano invece il paese verso la rovina. Ma mentre il mondo dei potenti e degli oppressori, mossi soltanto dalla sete di denaro e di potere, è quanto mai scontato e banale nella sua brutalità, quello dei miseri e degli oppressi, in costante rapporto con il mondo degli Invisibili e delle divinità tutelari, è di una straordinaria ricchezza, perché nutrito dal sapere stratificato di un popolo che dice apparentemente sì a tutto quanto di nuovo gli viene imposto, ma che resta pervicacemente legato ad una cultura ancestrale in cui affondano le radici della sua vita $\mathrm{e}$, dunque, la possibilità di continuare a vivere, mentre tutto intorno deperisce e muore, in senso proprio e figurato. Ci sono pagine straordinarie che ci descrivono questa immersione nel mistero di riti venuti forse dalla lontana Africa, in cui si ritrova-o meglio si ritrovava, perché i tempi stanno cambiando - una comunità che vi attinge un sia pur passeggero antidoto alla fame, alla fatica, alla violenza. Un grumo solido di credenze e di gesti rituali con cui i vari preti cattolici (che sono figure abbastanza positive nel romanzo) devono scendere a patti, perché capiscono che questa sacralità altra è parte integrante dell'identità di un popolo. Ci sono riti in cui si chiede la protezione degli dei e degli Invisibili, riti d'iniziazione e di passaggio da questa all'altra vita, c'è persino un rito in cui si officia il matrimonio con un dio, quello di Cilianise, zia di Cétoute, con Ogou, un matrimonio che riversa i suoi effetti benefici su tutta la comunità: «Les épousailles de tante Cilianise réconcilièrent Anse Bleue avec ses rêves anciens» (p. 233).

4 La grande sapienza di Yanick Lahens consiste nel far coesistere, su di uno stesso piano, la realtà tangibile e quella invisibile, perché entrambe fanno parte del vissuto haitiano e concorrono alla credibilità delle storie che scorrono e si intrecciano nel romanzo, sullo sfondo della storia tragica del Novecento: l'isola è infatti prima occupata dagli Americani, poi vittima dei Duvalier e infine zimbello del più subdolo dei profeti, quel Jean-Bertand Aristide che, pur di mantenere il potere, non esita a riaprire le porte dell'isola all'America. Il romanzo è una durissima denuncia dei potenti e un inno al popolo haitiano che continua a lottare per strappare qualche frutto ad una terra divenuta ormai sterile, governata da uomini avidi ed incapaci, che sembrano conoscere solo la brutalità e il tornaconto personale. La scrittura di Yanick Lahens è molto coinvolgente e sa farci entrare in sintonia con un universo che ci è totalmente estraneo, ma che ci affascina. La lingua, ora dolce ora aggressiva per modellarsi sugli eventi evocati, è pura poesia. 